\title{
Remembering Professor P. K. Appukuttan
}

\author{
S. Jagadeesh ${ }^{1} \quad$ Raman MV $^{1} \quad$ Sheeja Rajan ${ }^{1, \odot}$ \\ ${ }^{1}$ Department of Plastic Surgery, GMC Kozhikode, Kozhikode, Kerala, \\ India
}

Indian J Plast Surg 2021;54:381-382.

An excerpt from the poem "Little things" (Julia Carney, 1845) reads, "so the little moments, humble though they be, make the mighty ages, of eternity." Such were the humble efforts of many of our seniors, whose dedication and hard work led to the establishment of the pioneer departments of plastic surgery in our country. One of them was Professor P K Appukuttan, who laid the foundations of the plastic surgery specialty in northern Kerala. We were left saddened by his demise on the November 17, 2020.

Professor Appukuttan graduated from Government Medical College Thiruvananthapuram and joined as a Tutor in General Surgery at Kozhikode. He acquired his MS in Plastic Surgery from P W Medical College, Patna, under Prof. R. N. Sinha. After completing the course, he returned to Kozhikode and sowed the seeds for what would become the Department of Plastic and Reconstructive Surgery at the Government Medical College in Kozhikode, nursing it tenderly and watching it grow by leaps and bounds. He initiated plastic surgery work in the institution in 1968, with a specialty clinic which would receive referrals between $11 \mathrm{am}$ to $12 \mathrm{pm}$ only. A few beds were allotted for plastic surgery patients at the rear of a ward shared with urology and general surgery. The theater allotted was the side table of the general surgery operation theater twice a week. Yet, from the earliest of those days, he maintained meticulous handwritten records complete with illustrations on several of his surgical procedures, preserving the documents for posterity. From these humble beginnings, the department gradually expanded into a full-fledged 50-bedded plastic surgery unit under his diligent efforts.

Barring a short stint in Thiruvananthapuram, Dr. Appukuttan stayed on in Kozhikode and was the lifeblood of the department. Together with colleagues like Dr MV Raman, he worked painstakingly to create an independent department. MCh Plastic Surgery seats were sanctioned in 1980 and the department welcomed its first ever batch of MCh trainees Dr. Padmakumar and Dr. PT Punnose. The next challenge he overcame was to create a separate ward and theater complex for plastic surgery. He personally oversaw every stage

DOI https://doi.org/ $10.1055 / \mathrm{s}-0041-1736683$ ISSN 0970-0358
Address for correspondence Sheeja Rajan, MS, Mch, Department of Plastic Surgery, GMC Kozhikode, Kozhikode 673008, Kerala, India (e-mail: sheejarajantm@gmail.com).

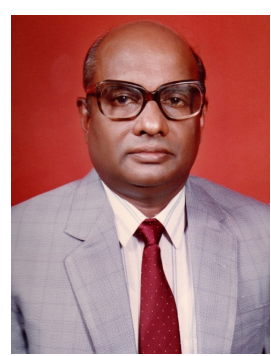

from designing to the actual construction process, in order to optimize the availability of natural light, ventilation and hygiene. The unique and utilitarian design of the plastic surgery ward and operation theater was a matter of personal pride to Dr. Appukuttan. He used to regale all his juniors with anecdotal stories of his many journeys to the state capital to procure official sanctions to build the facilities in the resource-constrained public sector hospital. Among his memorabilia were the big stack of entry passes to the state secretariat which he had preserved with utmost care.

The memories about his work practices shared by his students and coworkers are both deeply inspiring and immensely humbling. His colleagues remember him explaining the procedures in great detail to the patients and relatives. To him, no surgery was "minor," and each had its own complications and pitfalls. He used to keep abreast with the global trends in the field of plastic surgery. He would subscribe and read all issues of the PRS journal, which he would later donate to the department. To improve nursing care in the unit, he sent all his staff nurses to PGIMER Chandigarh for special training in plastic surgery. He would then order the new implants and devices from the catalogues and try to follow the surgical trends described in the literature. However, he used to shy away from public speaking and would stay away from podiums in scientific congresses and just let his work speak for him instead.

His teaching abilities were only surpassed by his surgical skill and acumen. He worked on developing new techniques and perfecting them. Along with Mohan M and Srinivasan A, he published a new technique of "earlobe reconstruction with a preauricular flap" in Plastic and Reconstructive Surgery journal in 1978. Another article by the same team, "A new technique of anchoring the mobilized mucoperiosteal flap to the underlying bone in cleft palate surgery" was published in the Indian Journal of Plastic Surgery in 1976. His technique of anchoring the tip of uvula to the posterior pharyngeal wall ( - Fig. 1) and the median mucoperiosteal turn-

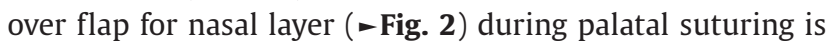
also well-known among peers. 


\section{New Method of Suturing Cleft Palate}

To get maximum retro position after trying the knot over the tip of uvula a bite is taken from the posterior pharyngeal wall and then fixed to the suture carrier. After repair of the palate is completed pull out the first stitch from the posterior pharyngeal wall and pull the stitch towards the tongue. The soft palate will not move freely but if you pull the stitch towards the nasal cavity it will move freely. This procedure helps getting good retro position of soft palate and easy movement of the soft palate backwards and upwards for effective separation of ori-pharynx from the nasopharynx.
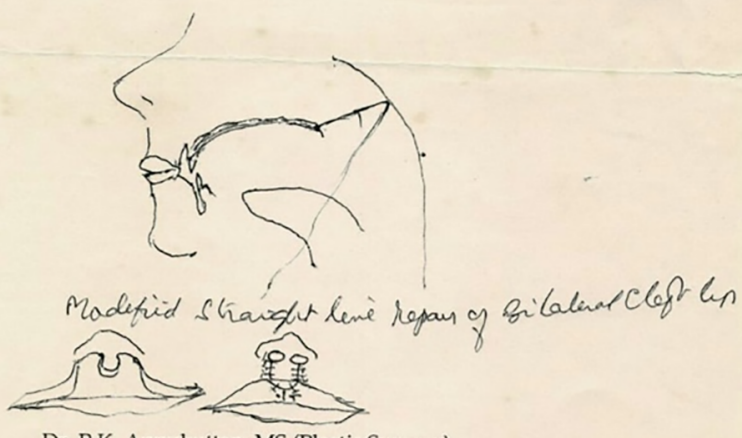

Dr. P.K. Appukuttan, MS (Plastic Surgery)

Retd. Professor of Plastic Surgery

Consultant, Baby Memorial Hospital

Calicut -673004 .

Fig. 1 Hand sketch of the anchoring suture from the tip of uvula to the posterior pharyngeal wall.

After retiring from government service, Professor Appukuttan continued working as a consultant at various private hospitals. He often waived his fee for the needy. He spearheaded efforts to introduce the Smile Train initiative to Kozhikode. He continued to perform surgeries well into his 70s, having performed a demanding procedure of 6 hours on a patient of acid burns of the face to restore appearance, whom many others had turned down. If Dr. Appukuttan was the father of the Department, his wife Mrs. Sarojini, a retired nurse, was definitely the mother. She made her love and support to the department profoundly felt with her parcels of homemade snacks and coffee for all on theater days. He is survived by his wife and three brilliant sons.

\section{NEW CLASSIFICATION OF COMPLETE CLEFT PALATE} (GROUP II)

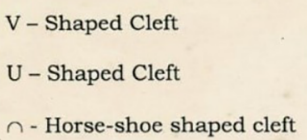

\section{Management:}

V-Shaped Cleft: $\longrightarrow$ 1. Dorance push back

U-Shaped Clef: $\quad$ Repair with a median muco-periosteal flap for

nasal layer at the hard palate level.

$n$ - Horse-shoe cleft: Bring tissue from elsewhere.

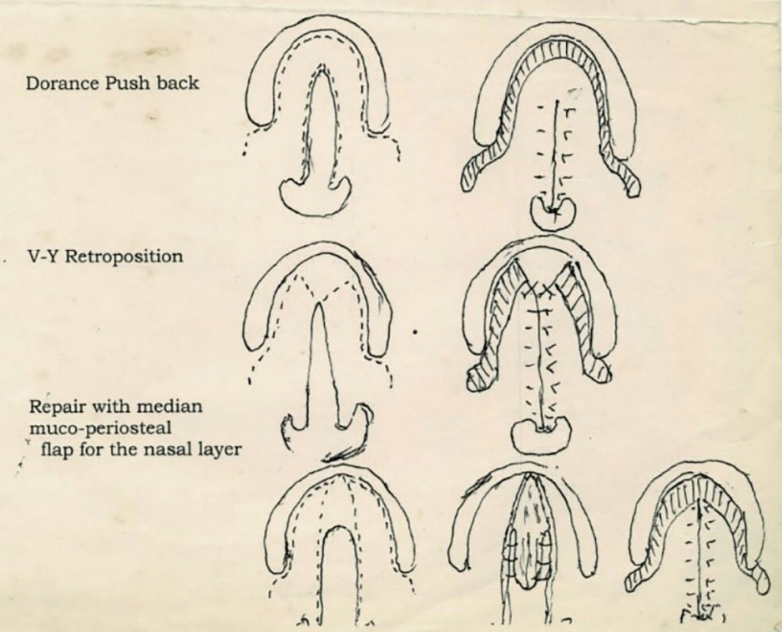

Fig. 2 Classification of palatal defects and preferred techniques for repair, including the median mucoperiosteal turnover flap for nasal layer in "U"- shaped clefts.

To see Prof. Appukuttan at work was to watch a master in action. His larger-than-life personality was well hidden beneath a humble demeanor and frugal life.

(compiled by Dr. Jagadeesh S [Former Professor \& Head of Plastic Surgery, GMC Kozhikode], Dr. Raman MV [Former Professor of Plastic Surgery, GMC Kozhikode], Dr. Sheeja Rajan [Professor \& Head of Plastic Surgery, GMC Kozhikode]). 